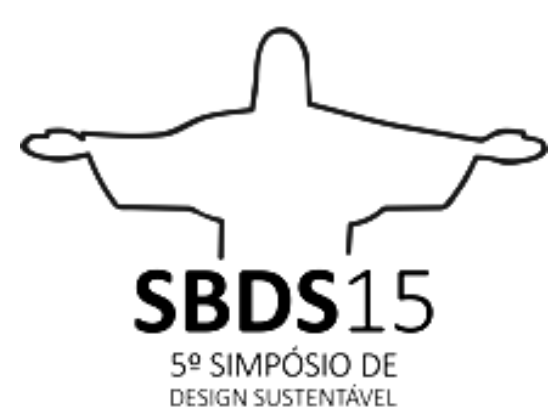

Rio de Janeiro, 11 de novembro a 13 de novembro de 2015.

\title{
A UTILIZAÇÃO DO MODELO TRIPLE TOP LINE ADAPTADO NA ANÁLISE CRÍTICA DAS AÇÕES DESENVOLVIDAS PELO LABORATÓRIO O IMAGINÁRIO DA UFPE:
}

aplicação ao artesanato cerâmico do cabo de santo agostinho em pernambuco

\author{
Tibério Tabosa \\ Laboratório de Design da UFPE, O Imaginário \\ ttabosa@hotmail.com \\ Virgínia Cavalcanti \\ Laboratório de Design da UFPE, O Imaginário \\ cavalcanti.virginia@gmail.com \\ Ana Maria Andrade \\ Laboratório de Design da UFPE, O Imaginário \\ anamariadeandrade@gmail.com \\ Germannya D'Garcia \\ Laboratório de Design da UFPE, O Imaginário \\ germannyadgarcia@gmail.com
}

Resumo: Sustentabilidade é um conceito relacional e sistêmico, que precisa se analisado de diversos pontos de vista e como ideia isolada não tem significado. Nas teorias tradicionais são focadas na tríade econômica, social e ambiental e são formuladas estratégias que são aplicadas e/ ou avaliadas em confronto com os impactos das ações humanas. Esse formato, contudo, geralmente encontra obstáculos que são quase insuperáveis dadas a complexidade dialética da temática. A busca incessante de soluções baseadas na visão dinâmica da interação entre as diferentes dimensões envolvidas é fundamental para a compreensão sistêmica do cenário da sustentabilidade em suas diversas nuances. Assumindo o ambiente complexo das inter-relações da sustentabilidade este artigo tem como objetivo tomar como base o Modelo proposto por McDonough e Braungard (2002 a ) para analisar criticamente as ações desenvolvidas Triple Top Line,pelo Laboratório O Imaginário da UFPE na comunidade produtora de artesanato cerâmico do Cabo de Santo Agostinho em Pernambuco. A abordagem metodológica tem a perspectiva dialética e também considera as dimensões da cultura e da prosperidade como complementares das 
dimensões originalmente propostas pelo Modelo. Os resultados utilizando o Modelo adaptado pelos autores através do uso dos fractais serviram para gerar novas perguntas bem como para o reconhecimento dinâmico de novas respostas. Do rebatimento do estudo de caso do Cabo de Santo Agostinho ao Modelo Triple Top Line adaptado, é possível afirmar que a gestão do design funciona como elo de sincronia e coesão das ações que permitiram alcançar as três dimensões da sustentabilidade: prosperidade/economia, equidade e meio ambiente/cultura.

Palavras-chave: Design, Artesanato, Sustentabilidade, Modelo Triple Top Line.

\begin{abstract}
Sustainability is an associative and systemic concept, which needs to be analyzed from different points of view and has no meaning as an isolated Idea. On traditional theories the focus is in the economic, social and environmental triad and there are strategies that area formulated, applied and evaluated and then compared with the impact of human actions. However, this configuration usually faces obstacles that are almost insuperable, given the dialectic complexity of the theme. The incessant search of solutions based on the dynamic vision of interaction between the different dimensions involved is fundamental to the systemic understanding of the sustainability scene in its diverse nuances. From this standpoint and presuming the sustainability inter-relations complex environment, this articles' purpose is to base the critical analyzes of the actions developed at Cabo de Santo Agostinho in Pernambuco - Brazil ceramic craftsmanship on McDonough and Braungard (2002 a) s Triple Top Line Model. The methodological approach considers the dialectic perspective and also takes in account culture and prosperity as proposed complementary dimensions by the original Model. The results obtained through the model s authors' adaptation using the fractals generated new questions to the dynamic acknowledgement of new answers. From the Triple Top Line model s adaptation to Cabo de Santo Agostinho - PE, Brazil ceramic craftsmanship case study, it is possible to say that the design management works as a link that syncs and provides cohesion to the actions and have allowed to reach the three dimensions of sustainability: prosperity/economy, equity and environment/culture.
\end{abstract}

Keywords: Design, craftsmanship, sustainability, Triple Top Line Model

\title{
1. INTRODUÇÃO
}

\subsection{A Produção de Bens e a Evolução do Conceito de Sustentabilidade}

A esfera da economia capitalista é definida por O'Connor (1989 p. 37) como "um conjunto de processos de produção de mercadorias, isto é bens e serviços, os quais são produzidos em processos diretamente controlados por agentes econômicos, utilizando outras mercadorias como inputs, cuja troca é regulada através de um integrado regime de preços". Esta visão determinística e focada no retorno econômico das inversões, tem enfoque dual e reducionista na medida em que considera, num extremo, a natureza como absolutamente inesgotável e, no outro, como barreira para expansão do capital. A mão de obra é considerada abundante o que viabiliza os exércitos de reserva possibilitando a manipulação da mobilidade laboral e o consequente pagamento de baixos salários.

No ambiente em que as cadeias produtivas formadas por fornecedores, colaboradores e consumidores já não apresentavam a garantia esperada de resultados econômicos contínuos e estáveis, além do observado incremento do cenário competitivo no universo das empresas; a 
obra seminal Cannibals with forks (Elkington, 2000) colocou, metaforicamente, a seguinte pergunta: "estaríamos diante do progresso se um canibal utilizasse um garfo?" ${ }^{1}$

Para responder a essa estranha, mas pertinente pergunta, Elkington propôs uma elaboração conceitual que visualiza o garfo com três dentes representando os três pilares da sustentabilidade, que para ele são: prosperidade econômica, qualidade ambiental e justiça social. Nessa visão, os pilares são observados de per si e pelas inter-relações entre seus pares. Surge assim, a abordagem do desenvolvimento sustentável cuja proposição básica é a eficiência econômica associada à eficácia social e ambiental.

Conceitualmente o Relatório Brundtland (1997) afirma que desenvolvimento sustentável é aquele que responde às necessidades do presente sem comprometer as possibilidades das gerações futuras de satisfazer as suas próprias..

O desenvolvimento não se reduz a um simples crescimento quantitativo; muito pelo contrário faz intervir e ressaltar a qualidade das relações humanas com o ambiente natural, e a necessidade de conciliar a evolução dos valores socioculturais com a rejeição de todo processo que leva a descaracterização cultural. Por outro lado é sustentável porque deve responder a equidade intrageracional e à intergeracional ${ }^{2}$.

O conceito de desenvolvimento sustentável se apoia no tripé econômico, social e ambiental e capta os fenômenos numa perspectiva tridimensional e interdisciplinar que se constitui numa visão coerente com a complexidade da questão superando a análise funcionalista binária, dual e determinista. Esse enfoque tridimensional responde aos quesitos da necessidade mínima e de suficiência para compreensão da realidade (Montibeller, 2004). A sustentabilidade é, portanto, um conceito relacional e sistêmico, que precisa ser analisado de diversos pontos de vista e como ideia isolada não tem significado. (MORIN, 2005).

Assumindo o ambiente complexo das inter-relações da sustentabilidade este artigo tem como objetivo tomar como base o Modelo Triple Top Line, proposto por McDonough e Braungard (2002a) para analisar criticamente as ações desenvolvidas pelo Laboratório 0 Imaginário da UFPE na comunidade produtora de artesanato cerâmico do Cabo de Santo Agostinho em Pernambuco. A metodologia de abordagem utilizada para a pesquisa é a dialética e o método de procedimento fundamental o estudo de caso tendo como instrumento de análise o Modelo Triple Top Line adaptado pelos autores.

\section{DESENVOLVIMENTO}

\subsection{A Gestão do Design no Universo da Sustentabilidade}

Em meio à produção de bens de consumo e cultura, o design atua como produtor de cenários passados, presentes e futuros. É uma atividade mediadora das relações entre fabricantes e consumidores, indústria e sociedade, produção e meio ambiente; que utiliza ferramentas, técnicas e modelos para configurar soluções inovadoras capazes de estimular um processo de mudança no comportamento desses agentes em favor de um direcionamento/ desenvolvimento centrado na sustentabilidade e seus três pilares tradicionais.

Kazazian (2005) reforça ainda a necessidade de uma abordagem sistêmica do design diante da atual complexidade na produção, consumo e descarte dos bens. Segundo esse autor, hoje não é possível mais falar em produto de forma isolada, exige-se mais e espera-se mais. $\mathrm{Na}$ tentativa de emergir tal necessidade, autores como Dias (2002) e Cortez e Ortigoza (2007) levantam as responsabilidades e conflitos sobre o desenvolvimento sustentável ao ressaltar o que hoje chamam de pegada ecológica, ou seja, "a pegada ecológica de um país, de uma cidade ou de uma pessoa, corresponde ao tamanho das áreas produtivas de terra e de mar,

\footnotetext{
${ }^{1}$ A pergunta original que aparece logo no início do prefácio do livro é a do poeta polonês Stanislaw Lec Seria progresso se um canibal utilizasse um garfo?

${ }^{2}$ Trata-se das relações de equilíbrio no atendimento das necessidades de sobrevivência entre os graus de descendência direta ou indireta no momento presente e no futuro
} 
necessárias para gerar produtos, bens e serviços que sustentam seus estilos de vida" (WWF, 2010).

Nesse sentido, a gestão de design, ou gerenciamento das ações e atividades do design buscando a eficiência e eficácia dos resultados, torna-se uma forte aliada na construção de resultados sistêmicos, ou seja, que englobem não apenas o artefato, mas toda a nuance que envolve sua concepção, produção, consumo, uso e descarte, assim como apresentam Martins e Merino (2008) e Manzini e Vezzoli (2008).

Manzini e Vezzoli (id., p.20-21), salientam ainda que o design, enquanto atividade de concepção de artefatos sob o enfoque da sustentabilidade, pode atuar em quatro níveis fundamentais de interferência, quais sejam:

- O redesign do existente - trata de melhorar o consumo de matéria e energia;

- Projetos de novos produtos e serviços que substituam os atuais - individualizar aqueles que oferecem os serviços ecologicamente mais favoráveis;

- Projetos de produtos-serviços intrinsecamente sustentáveis - oferece uma nova maneira (mais sustentável) que busque a obtenção de resultados socialmente apreciados e, radicalmente, favoráveis ao meio ambiente;

- A proposta de novos cenários que correspondam ao estilo de vida sustentável desenvolver atividades no plano cultural que tendam a promover novos critérios de qualidade e, em prospectiva, modificar a própria estrutura da busca de resultados. (Manzini e Vezzoli, 2008, p. 20-21)

A gestão do design, nesse cenário, pode colaborar para uma união harmônica de todos os níveis supracitados para se chegar a resultados mais consistentes.

\subsection{Modelo Triple Top Line}

A contribuição de Elkington (2000) denominada de Triple Botton Line é uma abordagem que permite a busca de um equilíbrio entre as dimensões econômica, social e ambiental.

Para aplicações em empreendimentos sociais (HART, 2005) propõe um enfoque calcado nos impactos econômico, ambiental e social representados em sub-triângulos onde são registrados os resultados mensuráveis positivos ou negativos das intervenções sociais em cada uma das dimensões. Representado pelo triângulo central, o guideline para o desenvolvimento das propostas de ação é o de que os problemas resolvidos devem ser maiores de que os novos problemas causados pela intervenção social.

Visando suportar o desenvolvimento de produtos (McDONOUGH e BRAUNGART, 2002a) propõem $O$ Modelo Triple Top Line considerando que as dimensões econômica, ecológica e equitativa devem ser representadas em fractais ${ }^{3}$ representados em sub-triângulos conforme apresentado na Figura 01. A ferramenta visual dos fractais busca compreender as inter-relações dinâmicas entre as dimensões econômica, ecológica e equitativa ao invés de apenas procurar encontrar o equilíbrio entre elas. A representação em fractais possibilita a geração de uma sequência lógica de perguntas visando reconhecer os impactos de uma dimensão e seu rebatimento nas demais.

\footnotetext{
${ }^{3}$ Entende-se que um fractal é uma forma sem escala aparente e composta por partes que são autorreferentes entre si. $\mathrm{O}$ fractal é uma ferramenta e não um símbolo e pode ser ativamente aplicada em desenvolvimento de projetos.
} 


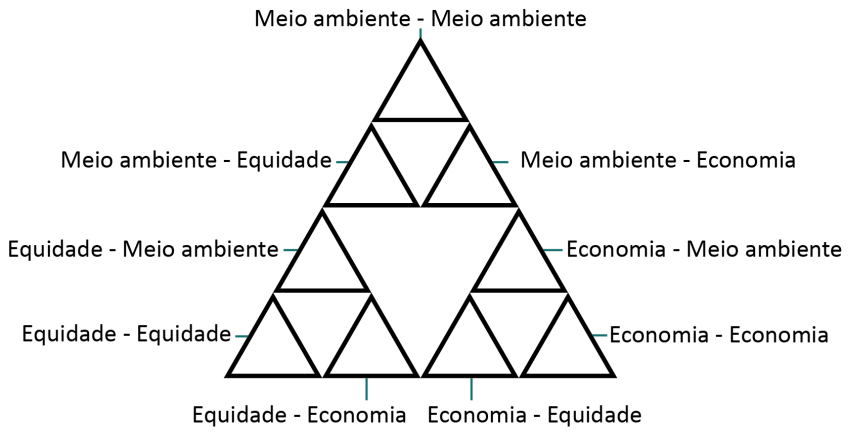

Figura 1 - Modelo Triple Top Line

Fonte: MCDONOUGH e BRAUNGART ( 2002a)

\subsection{O Modelo Triple Top Line Adaptado}

Considerando que o estudo de caso proposto trata de um trabalho de intervenção de design do Laboratório $O$ Imaginário em comunidades artesãs, o cenário de atuação identificado é o ambiente de empreendedorismo social. Segundo (MELO NETO e FROES, 2002) quando falamos de empreendedorismo social, estamos buscando um novo paradigma. 0 objetivo não é mais o negócio do negócio trata-se sim do negócio social, que tem na sociedade civil o seu principal foco de atuação e na parceria envolvendo a comunidade, governo e setor privado, sua estratégia.

A adaptação do modelo, como apresentado na Figura 02, tomou como base a formatação simplificada dos fractais proposta por (McDonough e Braugard, 2002b).

O conceito de prosperidade incorporado ao modelo pode ser definido como o conjunto de ações que favorecem e beneficiam os membros e as associações comunitárias de forma sustentável focando a intervenção social em ações que favoreçam a autonomia com liberdade responsável conforme proposto por (SEN, 1999).

Já para o conceito de cultura, partimos do entendimento que, a cultura de um povo comunica ao mundo sua identidade, valores e costumes, e afirma a sua existência. Encontra-se associada à valorização das raízes de cada comunidade, de forma que eventuais transformações estejam em sintonia com um contexto que permita a continuidade cultural. Uma vertente cultural é o artesanato, com produtos fabricados por artesão, primordialmente de forma manual. Em um mundo tecnológico e dinâmico, a valorização da tradição artesanal encontra barreiras na competitividade de produtos gerados com baixo custo e comercializados com uma boa margem de lucros. É cada vez maior a dificuldade de manter a produção do artesanato e a existência de artesãos, engajados socialmente e comercializando seus produtos de forma contínua.

Meio ambiente - Cultura

Cultura - Meio ambiente

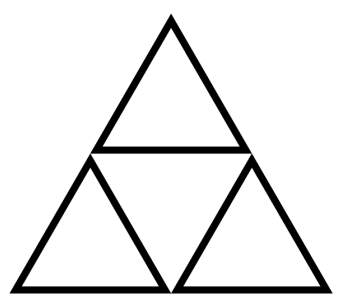

Equidade - Equidade Economia - Prosperidade

Equidade - Equidade Prosperidade - Economia

Figura 2 - Modelo Triple Top Line Adaptado: Meio Ambiente/ Cultura - Cultura/Meio Ambiente Fonte: MCDONOUGH e BRAUNGART (2002a) adaptado pelos autores 
No caso das intervenções com objetivos sociais, a perspectiva do tempo diz respeito ao médio e longo prazo e a dimensão espacial é essencialmente a do local podendo vir a ser em casos muito específicos o território.

\subsection{A ação do Laboratório $O$ Imaginário}

O Imaginário, Laboratório de pesquisa e extensão da Universidade Federal de Pernambuco, é formado por profissionais, professores e estudantes de diversas áreas do conhecimento com foco no design como instrumento a serviço da sustentabilidade ambiental, econômica e social. A atuação do laboratório contempla tanto a produção industrial quanto artesanal, esta última foco de interesse do artigo, e tem o objetivo de firmar a atividade artesanal em Pernambuco enquanto meio de vida sustentável, através de intervenções que respeitem os valores culturais das comunidades produtoras de artesanato.

A metodologia multidisciplinar tem sido usada em comunidades do litoral ao sertão pernambucano, com perfis diferentes e diversos estágios de organização e mobilização social. O foco do modelo de intervenção é a comunidade artesã e o seu produto e, a partir da construção do projeto coletivo, as ações são estruturadas com o apoio de cinco eixos: gestão ${ }^{4}$, produção ${ }^{5}$, design ${ }^{6}$, mercado $^{7}$ e comunicação ${ }^{8}$.

As questões transversais como qualidade e sustentabilidade perpassam todo o contexto como pode ser visualizado na Figura 03.

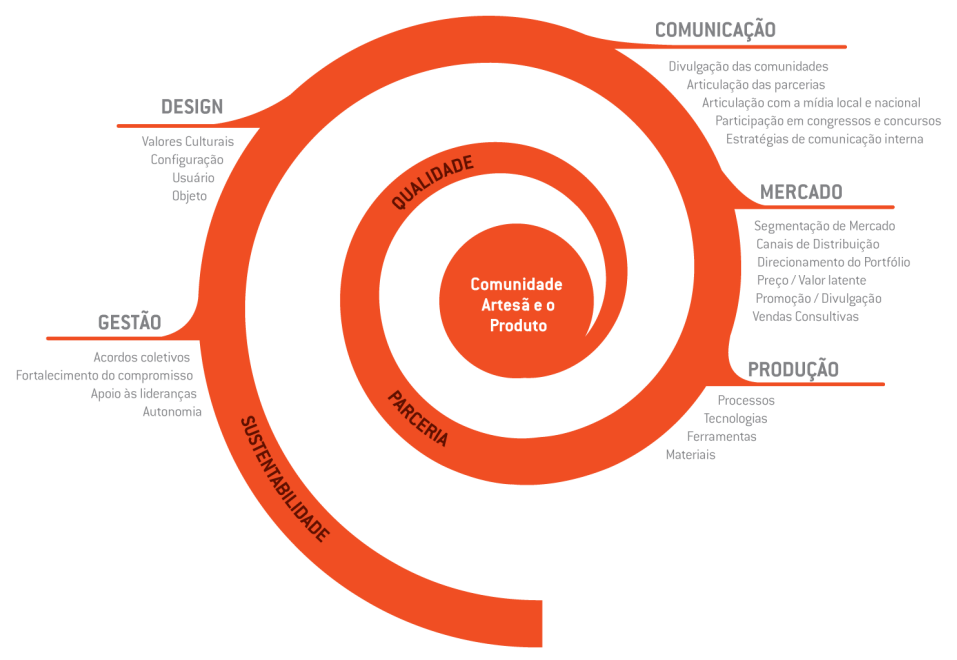

Figura 3 - Modelo desenvolvido pelo Laboratório 0 Imaginário

Fonte: Arquivo Laboratório O Imaginário (2012)

\footnotetext{
${ }^{4}$ Promove a articulação, a formação e o fortalecimento de grupos, incentivando a construção de acordos coletivos e a busca pela autonomia.

${ }^{5}$ Baseado nos modos de produção e no respeito ao ritmo de vida das comunidades. A inserção de novas tecnologias e ferramentas garante a qualidade do fazer artesanal e agrega valor ao produto.

${ }^{6}$ Cada peça é desenvolvida a partir da valorização do saber popular, do reconhecimento das tradições, habilidades e uso dos materiais.

${ }^{7}$ Direciona a produção das comunidades parceiras para segmentos específicos do mercado capazes de reconhecer o valor agregado ao produto.

${ }^{8}$ Para cada comunidade parceira do projeto é construída uma identidade visual que reafirma a história, a cultura e o sentimento de pertencimento a um grupo, imprimindo um selo de origem e qualidade ao que é produzido pela comunidade.
} 
A atuação do Imaginário apoia-se em uma estratégia metodológica participativa, a partir do entendimento que as artesãs e artesãos são sujeitos de suas práticas; coletiva, por meio do incentivo à construção de acordos coletivos e o reconhecimento de lideranças; individualizada, através do reconhecimento de habilidades e competências dos envolvidos; crítica, na medida em que leva artesãs e artesãos a fazer uma leitura de seu próprio fazer artístico; e contextualizante, já que a intervenção está calcada nas necessidades, desejos e no respeito aos valores identitários de cada comunidade artesã (ANDRADE et all 2006, p.30).

\subsection{0 caso do Cabo de Santo Agostinho}

O Cabo de Santo Agostinho situado na Zona da Mata Sul do Estado de Pernambuco abriga o maior polo industrial e portuário do Estado, um cenário de praias paradisíacas e manifestações culturais seculares. A produção cerâmica local teve origem no Brasil Colônia com a produção de tijolos e telhas utilizados nas edificações dos engenhos de cana-de-açúcar. A habilidade de trabalhar com argila e o torno é uma tradição que se mantêm ainda hoje e o município produz peças utilitárias e decorativas vendidas em todo o Estado.

A iniciativa da atuação do Imaginário foi uma reação ao desejo do grupo de ceramistas que buscavam possibilidades para vitrificar suas peças. Naquele momento os artesãos consideravam como alternativa a utilização de forno de baixa temperatura e esmaltes contendo chumbo na sua formulação, a exemplo do zarcão, prática recorrente em comunidades de oleiros do Estado.

A articulação entre o SEBRAE, a prefeitura local e o Laboratório O Imaginário permitiu ao grupo de ceramistas vislumbrarem alternativas ambientalmente corretas. A construção do novo projeto para o grupo foi coletiva e a participação dos artesãos voluntária. O grupo foi formado por artesãos, majoritariamente do sexo masculino, originários de antigas olarias, e contou com a participação do mestre Celestino Mota, o experiente e conhecido Sr. Celé.

O Cabo de Santo Agostinho é reconhecido como um reduto de ceramistas e oleiros habilidosos que são responsáveis pelo fornecimento de filtros, jarras e moringas para várias localidades do Estado e da região.
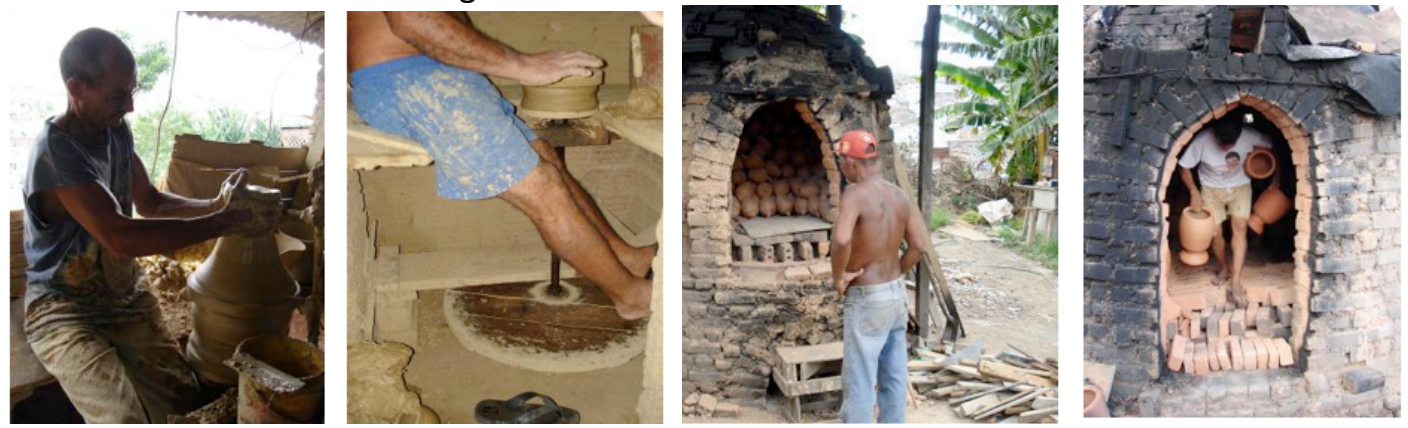

Figura 4, 5, 6 e 7 - Oleiros trabalhando no torno | Fornos à lenha - Mauriti

Fonte: Arquivo Laboratório O Imaginário (2012)

No primeiro momento, as visitas sucessivas dos técnicos do laboratório O Imaginário, ao espaço Mauriti, onde está localizado um conjunto de olarias, permitiram o reconhecimento das formas de fazer e conviver do grupo. A importância da liderança do Sr. Celé logo foi reconhecida. A formação do agrupamento de oleiros tem como particularidade a relação de parentesco. São irmãos, tios, primos, e sobrinhos que trabalham juntos, algumas vezes, em tarefas diferentes, mas na mesma atividade. Cada artesão - mestre tem o seu espaço, geralmente um galpão com tornos (figuras 04 e 05) e compartilham o espaço de beneficiamento, onde funciona uma única maromba, que fica próximo às baias onde a 
matéria-prima descansa. As edificações são muito rudimentares, para não dizer precárias, e as olarias e residências se confundem.

A queima é feita em três fornos de lenha que são usados por todos os artesãos do grupo conforme visualizado nas figuras 06 e 07 . 0 uso da madeira é um aspecto preocupante, pois muito embora seja utilizado material reaproveitado como restos de paletes, é possível ver outros tipos de madeira, possivelmente oriundas do que resta da mata atlântica naquela proximidade.

O barro, cuja da jazida pertence ao Complexo Portuário de Suape, tem qualidade plástica muito boa, e a extração é feita com a autorização da empresa Suape e da CPRH. O barro é doado e apenas a extração o transporte é que são pagos. A Associação dos Ceramistas do Cabo é responsável por indicar aquelas pessoas que irão retirar e transportar o material.

A Associação dos Ceramistas do Cabo foi fundada na década de oitenta e a questão da retirada do barro foi o fator mobilizador. Inicialmente foi bastante atuante, mas ao longo do tempo perdeu espaço político, sendo sua gestão pouco concorrida.

Foi diante desse cenário que os encontros e conversas com os artesãos levantaram aspectos favoráveis, desfavoráveis, oportunidades e ameaças que resultaram num plano de ação que contemplou questões de mercado, produção, produto e gestão.
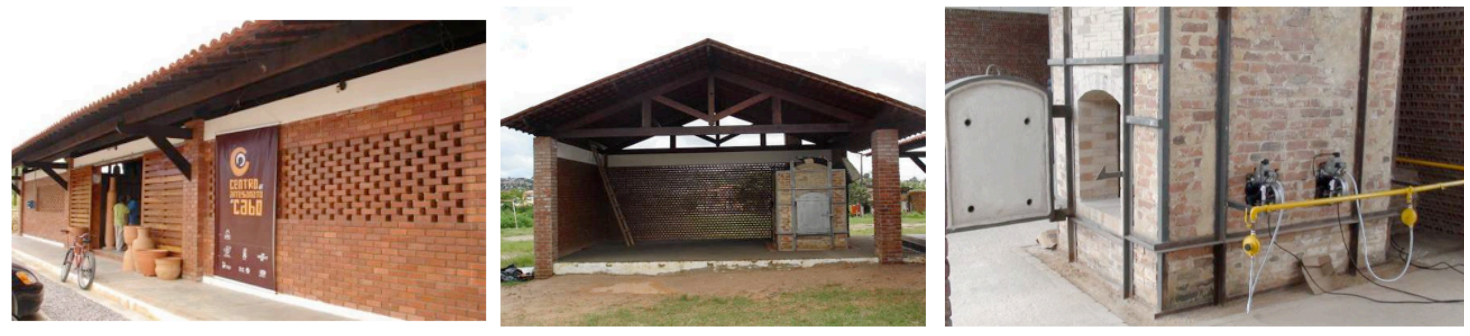

Figura 08, 09 e 10 - Fachada e instalações do Centro de Produção de Cerâmica Artesanal do Cabo Fonte: Arquivo Laboratório O Imaginário (2012)

O processo produtivo e os meios utilizados para a produção foram avaliados e objeto de diversos projetos complementares, apoiados por outros parceiros. Através da parceria com - Banco do Nordeste do Brasil foi possível viabilizar um forno alimentado a gás. A Prefeitura do Cabo de Santo Agostinho, além de disponibilizar o espaço para a construção do forno, construiu um novo Centro de Produção Artesanal (figuras 08, 09 e 10), segundo recomendações da equipe técnica do $\mathrm{O}$ Imaginário. O layout considerou o dimensionamento e os fluxos necessários para as atividades de produção (configuração, esmaltação, e queima), abastecimento e distribuição.

A troca da madeira pelo gás natural foi possível com o apoio da Companhia Pernambucana de Gás - COPERGÁS. O uso do gás possibilita a queima em alta temperatura, atende os requisitos ambientais e garante a qualidade dos produtos (figuras 09 e 10).

Um novo torno elétrico foi desenvolvido em parceria com o Ministério da Ciência e Tecnologia. O projeto é resultado da análise de uso dos tornos convencionais, no qual o posicionamento do eixo dificulta o posicionamento do oleiro. 0 novo torno afasta o eixo que apoia o prato rotativo, permitindo que o oleiro se posicione de frente para o torno sem 0 desconforto de ter o eixo entre as pernas. Oito novos tornos foram construídos para que os mestres compartilhem o saber com jovens da comunidade e dessa forma a tradição e o gosto pela atividade.

A vitrificação, motivação primeira do grupo, demandou do grupo mais pesquisas. A parceria com o SENAI viabilizou a vinda de um estudante e técnicos que iniciaram as pesquisas 
de esmaltação. Nos dias de hoje, além dos esmaltes criados e testados, um novo grupo de jovens foi capacitado para manipulação e aplicação dos esmaltes.

Nessa fase foi possível incluir mulheres, que até então só tinham sido envolvidas quando da participação em feira e exposições.

No projeto inicial uma nova maromba (equipamento de laminação e extrusão a vácuo) mais potente seria instalada no espaço Mauriti. A matéria prima beneficiada seria transportada para o Centro de Produção, entretanto, a dificuldade de acesso de caminhões ao espaço Mauriti, forçou uma mudança. Assim, foi acrescida ao Centro de Produção uma área de beneficiamento para instalação da nova maromba (figuras 11 e 12). Esse equipamento, permitiu também a incorporação de resíduo de indústria cerâmica à matéria prima original. $A$ mistura resultante além de contribuir para diminuir do uso do recurso natural, permitindo a extração da jazida por mais tempo, apresenta ótimos resultados tanto em relação à plasticidade quanto a porosidade da mistura.
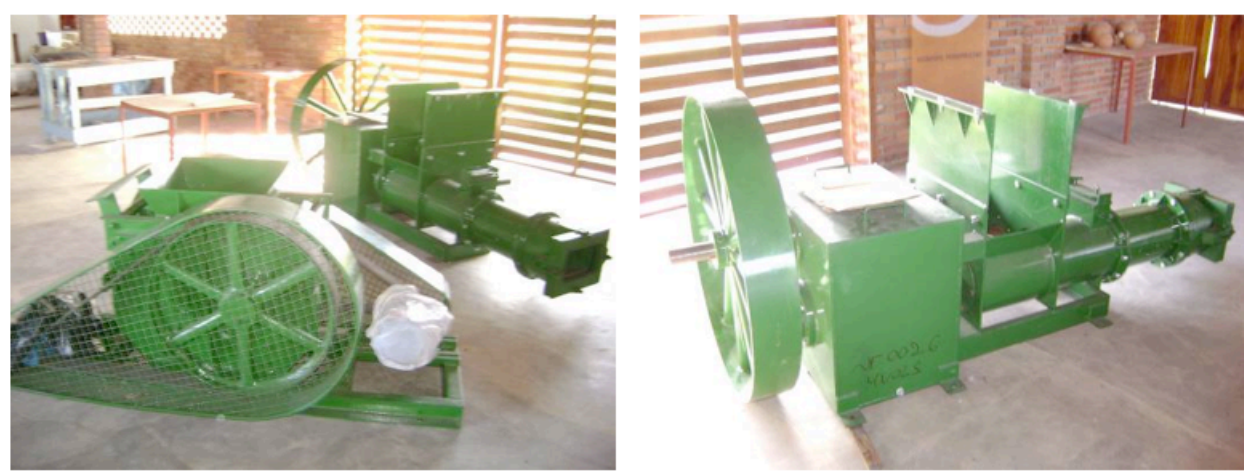

Figura 11 e 12 - Equipamentos de laminação e Extrusora a vácuo

Fonte: Arquivo Laboratório O Imaginário (2012)

O diálogo entre designers e artesãos alimentou o desenvolvimento de novos produtos (figura 13). Compreender habilidades, reconhecer as referências, conhecer mercados, discutir preços, foram argumentos para que os artesãos criassem novas formas de peças utilitárias que valorizam a cultura do local, agregando maior valor de mercado. CERAMISTAS DO CABO é o nome do grupo e a imagem do oleiro e do torno representa o grupo. A marca é aplicada em cartões de visita, etiquetas, embalagens e todo o material de apoio como talonários de pedido, recibos entre outros (Figuras 14 e 15). A criação da marca reforçou o sentimento de grupo ao mesmo tempo em que tornou o produto melhor posicionado no mercado.
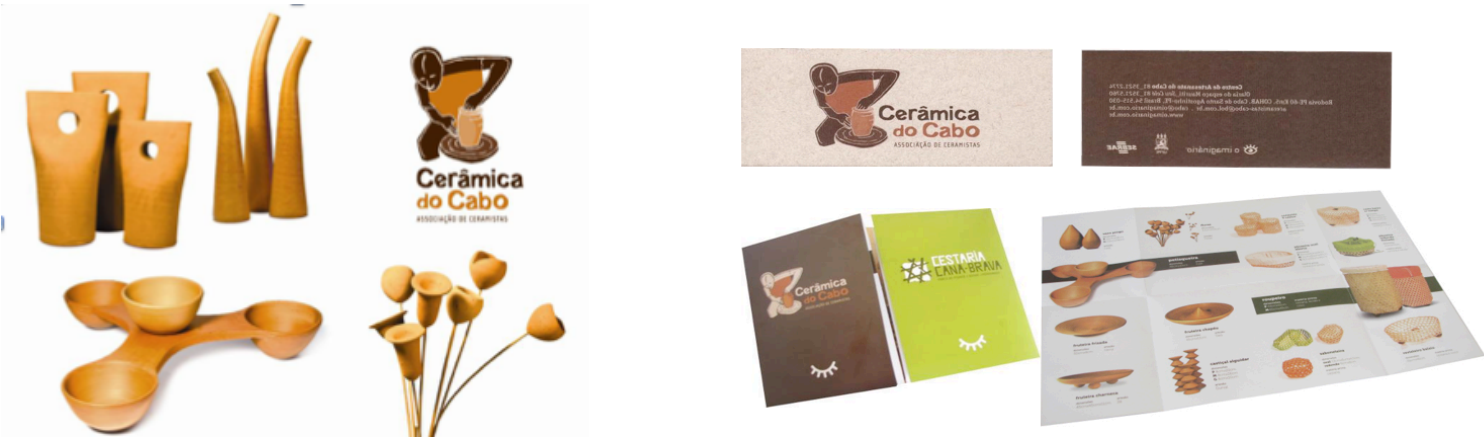

Figura 13, 14 e 15 - Produtos desenvolvidos em parceria entre os artesãos e os membros do Laboratório 0 Imaginário | Material gráfico produzido para disseminação dos produtos Fonte: Arquivo Laboratório O Imaginário (2012)

As relações entre os artesãos, designers, técnicos nesse processo já chega perto de 12 anos. É possível observar que o incentivo a gestão colegiada é mais rica no que diz respeito à 
qualidade das decisões, no entanto, demanda um tempo maior. Apesar do uso coletivo de espaços e equipamentos, o comprometimento e a corresponsabilidade entre artesãos ainda é frágil.

A gestão colegiada é o modelo discutido para a gestão do Centro de Artesanato e inclui, além do representante da Associação e do grupo Ceramistas do Cabo, representantes da universidade, do SEBRAE, da Prefeitura do Cabo e das empresas parceiras. O papel do colegiado é auxiliar no planejamento do Centro na busca de parcerias que irão ampliar o diálogo dos artesãos com o seu entorno e com o mercado.

Em Setembro de 2013 iniciou-se um novo projeto de intervenção patrocinado pela Petrobras dentro do Programa Socioambiental com duração de dois anos com a visão estratégica de observando a produção artesanal como um negócio sustentável preparar o grupo e instalar a infraestrutura necessária no Centro de Produção Artesanal para a autonomia e a autodeterminação dos participantes da iniciativa atuando de forma coletiva.

\subsubsection{Aplicação do Modelo Triple Top Line adaptado ao Caso do Cabo de Santo Agostinho}

Diante da descrição sobre a comunidade do Cabo de Santo Agostinho e a intervenção do laboratório O Imaginário, a aplicação do modelo adaptado pode ser visualizada no Quadro 01 apresentado abaixo que estabelece uma comparação das três dimensões já incorporadas aos conceitos de prosperidade e cultura.

Quadro 1 - Aplicação Modelo do Triple Top Line adaptado ao caso do Cabo de Santo Agostinho/PE

\begin{tabular}{lll}
\hline Prosperidade/ Economia & Equidade & Meio ambiente/ Cultura \\
\hline Como o uso de novos recursos & Apropriação dos recursos & Uso racional da matéria-prima \\
tecnológicos pode favorecer a & com a inclusão de novos & (menos perda no processo de \\
prosperidade do grupo? & participantes no grupo. & queima)
\end{tabular}

\begin{tabular}{lll} 
& & $\begin{array}{l}\text { Valorização das referências } \\
\text { locais }\end{array}$ \\
\hline $\begin{array}{l}\text { Melhoria da qualidade do } \\
\text { produto pela qualificação } \\
\text { profissional e incorporação de } \\
\text { jovens no mercado de trabalho }\end{array}$ & $\begin{array}{l}\text { Como as novas tecnologias } \\
\text { geram impacto no processo } \\
\text { de produção coletiva? }\end{array}$ & $\begin{array}{l}\text { Retirada controlada do } \\
\text { material na jazida. }\end{array}$ \\
& & $\begin{array}{l}\text { Promover a sobrevivência da } \\
\text { cultura através da re- } \\
\text { significação da tradição. }\end{array}$ \\
\hline $\begin{array}{l}\text { Uso sustentável da matéria- } \\
\text { prima: manejo da jazida e } \\
\text { processamento e uso do refugo } \\
\text { de cerâmica industrial. }\end{array}$ & $\begin{array}{l}\text { Compartilhar saberes e } \\
\text { solidariedade na formação do } \\
\text { grupo. }\end{array}$ & $\begin{array}{l}\text { Qual o impacto do uso da } \\
\text { matéria-prima no fazer } \\
\text { artesanal e na preservação da } \\
\text { cultura e tradições locais? }\end{array}$ \\
\hline
\end{tabular}

Fonte: Elaborado pelos autores, com base na pesquisa realizada

A metodologia de intervenção do Laboratório O Imaginário apresentada na Figura 03 tem sido sistematicamente testada e ajustada às particularidades da abordagem do trabalho em comunidades. Nesse sentido, as perspectivas analíticas pelas dimensões econômica, ambiental e social têm sido à base do desenvolvimento conceitual e da inovação social obtida.

A visão crítica sobre a metodologia em uso oferecida pelo modelo Triple Top Line adaptado com as inclusões dos fatores prosperidade e cultura através da ferramenta dos fractais serviram para dialeticamente gerarem novas perguntas bem como o reconhecimento dinâmico de novas respostas. Dentro dessa visão, foram fortalecidos o valor econômico e a 
qualidade dos produtos desenvolvidos ao mesmo tempo em que novos processos e infraestruturas possibilitaram eficácia nos impactos ambientais e culturais.

Quadro 2 - Indicadores de Valores Adicionais

\begin{tabular}{|c|c|c|}
\hline & Filtro & Totem Iluminado \\
\hline $\begin{array}{l}\text { Etapas da produção } \\
\text { (Quantidade) }\end{array}$ & 07 & 04 \\
\hline Matéria- Prima (R\$) & 1.12 & 0,45 \\
\hline Acabamento (R\$) & 0.10 & 0,02 \\
\hline Homens x Horas (Quantidade) & 1.72 & 1.19 \\
\hline Valor hora (R\$) & 2.18 & 20,78 \\
\hline Valor de mercado (R\$) & 5.00 & 25,00 \\
\hline Indicador de valor adicionado & 1.00 & 9,52 \\
\hline
\end{tabular}

Fonte: Elaborado pelos autores, com base na pesquisa realizada

\section{CONCLUSÃO}

A comparação entre o filtro, tradição produtiva local, e um totem luminária apresentada no quadro 02 exemplifica o impacto do trabalho impulsionando pelo Laboratório O Imaginário, o qual valorizado a participação comunitária e a criação coletiva, compartilha novos conceitos e tecnologias que adicionam valor a partir da avaliação e exploração das fronteiras do mercado.

As ações desenvolvidas pelas parcerias estabelecidas no Cabo de Santo Agostinho junto ao grupo de ceramistas demonstram o rebatimento das dimensões propostas na adaptação do Modelo Triple Top Line, assim como demonstra o Quadro 01.

As perguntas elaboradas com o intuito de verificar sua compatibilidade com o cenário investigado tiveram como resposta a confirmação de que a intervenção está alinhada ao equilíbrio nas relações entre meio ambiente/ cultura $\mathrm{x}$ prosperidade/ economia $\mathrm{x}$ equidade.

Dentro do contexto analisado, no entanto, é preciso reconhecer que existem oportunidades por se capitalizar na dimensão prosperidade/economia pelo viés da comercialização, tendo em vista a baixa visibilidade de vários nichos de mercado no atual nível de desenvolvimento do segmento artesanal do Brasil. Essa é uma vertente auspiciosa para o processo de intervenção e pode ser trabalhada por meio de estratégias de adição de valores e a identificação de nichos de mercados distintos capazes a reconhecer e pagar por esses valores como já se pode observar, ainda que de forma inicial, nas oportunidades de mercado capturadas pela aplicação das esmaltações e na aplicação de design no desenvolvimento 
coletivo de peças dirigidas a segmentos mais sofisticados do mercado, notadamente na áreas de utilitários para gastronomia e jardinagem de hobby, já reconhecidas em concursos do tipo Top 100 Sebrae, citações em revistas especializadas e recomendações por especialistas nas áreas de ambientação e decoração.

Ainda de acordo com o case estudado, é fator preponderante a busca por resultados sistêmicos que visem o equilíbrio das dimensões do Modelo Triple Top Line adaptado, o uso da gestão de design no sentido amplo das ações do Laboratório O Imaginário; especialmente no que se refere aos eixos do modelo de atuação: produção, comercialização, design, comunicação e gestão.

Do rebatimento do estudo de caso do Cabo de Santo Agostinho ao Modelo Triple Top Line adaptado, já é possível afirmar que a gestão do design funciona como elo de sincronia e coesão das ações que permitirá alcançar as três dimensões da sustentabilidade: prosperidade/economia, eqüidade e meio ambiente/cultura.

\section{REFERÊNCIAS}

ANDRADE, Ana Maria Q. de et al. Imaginário Pernambucano: design, cultura, inclusão social e desenvolvimento sustentável. Recife: Zoludesign, 2006.

BRUNDTLAND, A. Relatório da Comissão Mundial sobre Meio Ambiente e Desenvolvimento. New York: ONU, 1887

CORTEZ, Ana Tereza Caceres; ORTIGOZA, Sílvia A. G. Consumo Sustentável: conflitos entre necessidade e desperdício. São Paulo: UNESP, 2007.

DIAS, Genebaldo Freire. Pegada Ecológica e Sustentabilidade Humana. São Paulo: Gaia, 2002. ELKINGTON, J. Cannibals with forks. New York: Capstone Publishing Limited, 2000

HART, S. Capitalism at the crossroads: the unlimited opportunities in solving the World's most difficult problems. New York: Pearson Education, Inc , 2005.

KAZAZIAN, Thierry. Haverá a Idade das Coisas Leves: design e desenvolvimento sustentável. São Paulo: Senac, 2005.

MARTINS, Rosane Fonseca de Freitas; MERINO, Eugenio André Diaz. Gestão de design como estratégia organizacional. 1a ed. Londrina: Eduel, 2008.

MANZINI, EZio; VEZZOLI, Carlo. O Desenvolvimento de Produtos Sustentáveis: os requisitos ambientais dos produtos industriais. São Paulo: Universidade de São Paulo, 2008.

McDONOUGH W and BRAUNGARD M. Design for the Triple Top Line: New Tools for

Sustainable Commerce. Corporate Environmental Stategy, Vol 9, No. 3, 2002 a

McDONOUGH W and BRAUNGARD M. Cradle to Cradle: Remaking the Way We Make Things.

New York, 2002 b

MELO NETO, Francisco e FROES, César. Empreendedorismo social: a transição para a

sociedade sustentável. Rio de Janeiro: Qualitymark, 2002.

MONTIBELLER Filho, G. O Mito do Desenvolvimento Sustentável: Meio ambiente e custos

sociais no moderno sistema produtivo de mercadorias. Florianópolis:Editora da UFSC, 2004

MORIN, Edgar. Introdução ao pensamento complexo. Porto Alegre:Sulina, 2005..

O' CONNOR, J. Political economy of ecology of socialism and capitalism. Capitalism, nature, socialism, No. 3, p. 93-106, 1989

PASA, Carla e GOMEZ, Leonardo. A congruência entre indicadores de sustentabilidade e o

Triple Top Line. Anais do XI Simpósio de Administração da Produção, Logística e Operações.São Paulo,2008.

SEN, A. Development as freedom. New York: Random House, Inc, 1999

WWF. Pegada Ecológica? 0 que é isso? Disponível em:

http://www.wwf.org.br/wwf_brasil/pegada_ecologica/ 